\title{
Giant Congenital Melanocytic Nevi: A Case Report and Review of Literature
}

\author{
Piparsania $S^{1}$, Singh $S^{2}$, Mahashabde $S^{3}$, Raipurkar $S^{4}$ \\ ${ }^{1}$ Dr. Saurabh Piparsania, Assistant Professor, ${ }^{2}$ Dr. Saurabh Singh, PG $3^{\text {rd }}$ Year, ${ }^{3}$ Dr. Shubhangi Mahashabde, Senior \\ Resident, ${ }^{4}$ Dr. Swati Raipurkar, Professor and Head. All authors are affiliated with Department of Pediatrics, Index \\ Medical College, Hospital and Research Centre. Indore, M. P, India.
}

Address for Correspondence: Dr. Saurabh Piparsania, 46, Goyal Avenue, Near DPS and Ashirwad Vila, Nipania, Indore, M. P. Email- sourabhpiparsania@gmail.com

\begin{abstract}
The congenital melanocytic nevi which are formed by the overgrowth of melanocytes occur in about $1 \%$ of the newborns. Giant Congenital Melanocytic Nevi (GCMN) which are of sizes larger than $20 \mathrm{~cm}$ diameter are rare and they occur in 1/500,000 newborns. Primary diagnosis of congenital giant nevus is clinical. Here, we report a case of full-term infant born with extensive black patch having smooth surfaces, irregular margins, and covering $45 \%$ of the skin surface.
\end{abstract}

Keywords: Congenital, Giant, Melanoma, Nevi, Neurocutaneous.

\section{Introduction}

GCMN are rare, disfiguring lesions present at birth associated with complications of malignant melanoma and neurocutaneous melanosis. Congenital melanocytic nevi are brown to black moles which are commonly found over the back and the thigh areas [1]. These lesions are also known as bathing trunk, coat sleeve or stocking nevi, depending on their regional distribution [2]. The risk of malignant melanoma for the giant nevi is approximately $5-10 \%$; treatment may include surgical and non-surgical procedures, psychological intervention and/or clinical follow-up, with special attention to changes in color, texture or on the surface of the lesion [3]. The case report of GCMN is being reported because of its rarity and evolving methods of management along with a review of the literature.

\section{Case Report}

A full-term, $2.6 \mathrm{Kg}$, male baby born out of a nonconsanguineous marriage vaginally by vertex presentation to a multigravida mother, with an uneventful antenatal history, presented with an extensive hyper-pigmented patch over the body since birth. The length and head circumference of the baby were $49 \mathrm{cms}$ and $34 \mathrm{cms}$ respectively, at birth. On

Manuscript received: $6^{\text {th }}$ May 2016

Reviewed: $15^{\text {th }}$ May 2016

Author Corrected; $28^{\text {th }}$ May 2016

Accepted for Publication: $17^{\text {th }}$ June 2016 physical examination of the newborn, an extensive large black patch involving neck, anterior half of the chest and abdomen, upper arm posteriorly and back, covering $45 \%$ of the skin surface was noted (Figure1 and Figure 2). The nevus had a smooth surface and irregular margins. There were no other congenital anomalies. The neurological examination was normal. There was a negative family history of similar lesion. Other examinations and surveys including X-ray of the spine, fundus examination and transcranial and abdominal ultrasonography were normal. Baseline magnetic resonance imaging (MRI) was normal. The biopsy of the lesion was taken and the histopathological findings were consistent with those of congenital melanocytic nevi. No evidence of a malignant transformation was seen. The baby was discharged with the advice to parents for staged excision and skin grafting.

\section{Discussion}

The congenital melanocytic nevi are pigmented cutaneous lesions formed by a combination of epidermally and dermally derived nevus cells occurring in about one per cent of the newborns. They are classified according to their size as small $(<1.5 \mathrm{~cm})$, medium $(1.5-19.9 \mathrm{~cm})$ and large or giant nevi $(>20$ $\mathrm{cm})$. Giant congenital nevi or giant hairy nevi have an irregular margin often with a verrucous surface. 
Satellite lesions are often present beyond the periphery of the main lesion and may be scattered over the entire skin surface. Giant hairy nevi on the scalp and neck may be associated with leptomeningeal melanocytosis

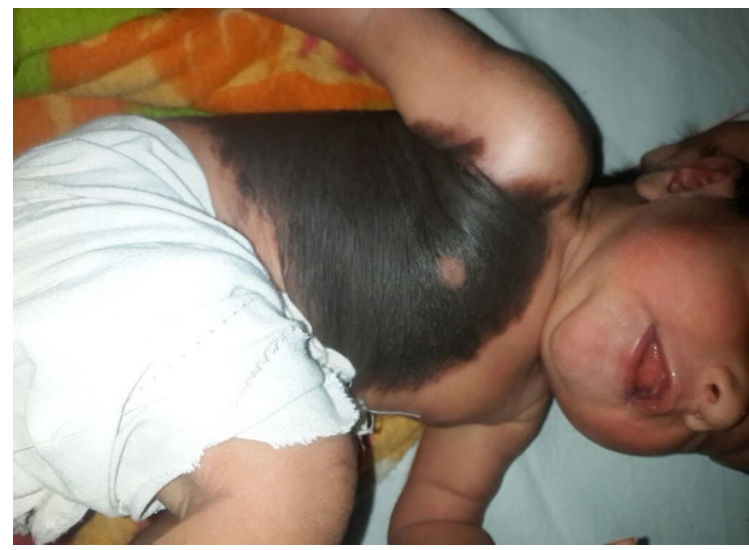

and neurologic disorders that include neurofibromatosis, epilepsy or focal neurologic abnormalities.

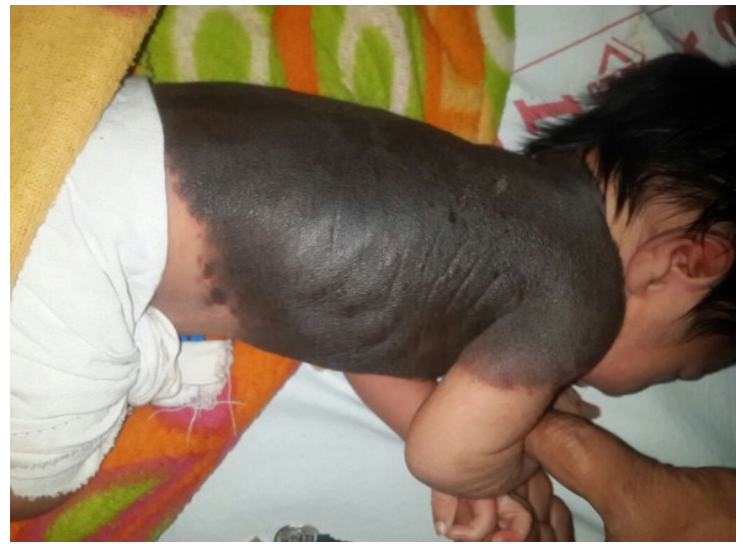

Figure: 1 \& 2: Showing an extensive large black patch involving neck, anterior half of the chest and abdomen, upper arm posteriorly and back.

The incidence for small nevi is 1 in 100 births; for medium nevi 6 in 1000 births; a GCMN larger than $20 \mathrm{~cm}$ in diameter occur in 1 per 500,000 newborns [4,5]. An equal prevalence exists in males and females. GCMN are thought to be caused by spontaneous mutations or other events during fetal development, but in some families, the frequent appearance of these lesions suggest that they may be genetically inherited. Findings of a culture of melanocytes from such a lesion showed chromosome rearrangements involving $1 \mathrm{p}, 12 \mathrm{p}$, and 19p. Over expression of HGF/SF (hepatocyte growth factor/scatter factor) is associated with disorders of differentiation, proliferation and migration of melanocytes and could be related to the occurrence of GCMN. Histologically, nevi are transformed melanocytes, which are normally highly dendritic cells interspersed among basal keratinocytes.

The incidence of malignant potential in these lesions varies from 2-41\% [6]. The size of the lesion correlates with the potential for malignant transformation. The risk of malignancy is also increased by the presence of larger nevi (greater than $50 \mathrm{~cm}$ ), axial location such as trunk, head and neck, the presence of multiple satellite lesions, and the existence of nodules, dark patches, junctional activity, deep dermal neurogenic element or a blue nevus component. The risk of malignant melanoma in patients with small to medium ones range from $2.6 \%$ to $4.9 \%$, while for giant nevi the risk is approximately $6 \%$ [7]. The impact of GCMN is greater because of the considerable cosmetic disfiguration along with its higher malignant potential. Radiographic imaging, including serial MRI, is warranted to evaluate melanocytic depositions in the CNS.

The management and treatment of patients with GCMN remains controversial. No absolute guidelines can be recommended. Management is individualized and centered around: size of the lesion, age of the patient, risk of neoplastic proliferation, cosmetic appearance, possible functional impairments resulting from invasive procedures and the psychological impact on the patient and family [4,8]. Aesthetic considerations are important. It is impractical to prophylactically excise all non-giant congenital nevi; yearly examination for the first 3 years of life is recommended, with reassessment every 2 to 5 years afterwards depending on the confidence of the parents to monitor the lesions. Surgical treatment of GCMN is addressed at age 6 months. Treatment options for removal of the GCMN in pediatric population include serial excision and reconstruction with skin grafting, tissue expansion, local rotation flaps, and free tissue transfer [9]. Adjunctive treatment options include chemical peels, curettage, dermabrasion, and laser surgeries. Thus, treatment of patients with GCMN may include surgical or non-surgical procedures, psychological and / or clinical interventions, with the utmost attention in changes of color, texture or in the surface of the lesion. At present, there is no current evidence that the removal of the nevus has a prophylactic role against the onset of melanoma $[10,11]$.

Funding: Nil, Conflict of interest: Nil

Permission from IRB: Yes 


\section{References}

1. Walton RG, Jacobs AH, Cox AJ. Pigmented lesions in newborn infants. Br J Dermatol. 1976 Oct; 95 (4): 389-96.

2. Caro William A. Tumours skin, In: Dermatology, Edited by Moschello SL, Pillshury DM, Hurley HJ, WB Saunders Company, Philadelphia, 1978, p. 1323-1407.

3. Viana AC, Gontijo B, Bittencourt FV. Giant congenital melanocytic nevus. An Bras Dermatol. 2013 Nov-Dec;88(6):863-78. doi: 10. 1590/ abd 1806-4841. 20132233.

4. Rhodes AR. Melanocytic precursors of cutaneous melanoma. Estimated risks and guidelines for management. Med Clin North Am.1986 Jan;70(1):3-37.

5. Rhodes AR, Weinstock MA, Fitzpatrick TB, Mihm MC Jr, Sober AJ. Risk factors for cutaneous melanoma. A practical method of recognizing predisposed individuals. JAMA. 1987 Dec 4;258(21):3146-54.

6. Reed WB, Becker SW Sr, Becker SW Jr, Nickel WR. Giant pigmented nevi, melanoma, and leptomeningeal melanocytosis : A clinical and histopathological study.
Arch Dermatol. 1965 Feb; 91:100-19.

7.Rhodes AR, Melski JW. Small congenital nevocellular nevi and the risk of cutaneous melanoma. J Pediatr. 1982 Feb; 100(2): 219-24.

8. Tannous ZS, Mihm MC Jr, Sober AJ, Duncan LM. Congenital melanocytic nevi: clinical and histopathologic features, risk of melanoma, and clinical management. J Am Acad Dermatol. 2005 Feb; 52(2): 197-203.

9. Iconomou $\mathrm{T}$, Michelow BJ, Zuker RM. Tissue expansion in the pediatric patient. Ann Plast Surg. 1993 Aug; 31(2):134-40.

10. Kinsler V, Bulstrode N. The role of surgery in the management of congenital melanocytic naevi in children: a perspective from Great Ormond Street Hospital. J Plast Reconstr Aesthet Surg. 2009 May; 62 (5):595-601. doi: 10.1016/j.bjps.2008.12.016. Epub 2009 Feb 25.

11. Krengel S, Hauschild A, Schäfer T. Melanoma risk in congenital melanocytic naevi: a systematic review. Br J Dermatol. 2006 July; 155(1):1-8.

\section{How to cite this article?}

Piparsania S, Singh S, Mahashabde S, Raipurkar S. Giant Congenital Melanocytic Nevi: A Case Report and Review of Literature. Int J Pediatr Res.2016;3(7):479-481.doi:10.17511/ijpr.2016.i07.02. 